\title{
Effect of bovine respiratory disease during the receiving period on steer finishing performance, efficiency, carcass characteristics, and lung scores
}

\author{
B. K. Wilson, ,1 PAS, D. L. Step,† C. L. Maxwell,, C. A. Gifford, ${ }^{*}$ C. J. Richards, ${ }^{*}$ and C. R. Krehbiel, ${ }^{*}$ PAS \\ *Department of Animal Science, and †Department of Veterinary Clinical Sciences, Oklahoma State University, \\ Stillwater 74078
}

\begin{abstract}
Bovine respiratory disease (BRD) is responsible for the majority of morbidity, mortality, and production losses occurring in feedlots. This experiment evaluated the effects of BRD incidence on subsequent finishing performance, efficiency, carcass characteristics, and lung scores of steers. Crossbred steers $(\mathrm{n}=516)$ were monitored daily for clinical signs of BRD (BRD attributed morbidity and mortality were 66.5 and $13.2 \%$, respectively). A subset of calves $(\mathrm{n}=174)$ were grouped by the number of times treated for BRD (BRDX) and randomly allocated to finishing pens. The BRDX experimental groups included never treated for BRD (0X; 8 pens) and treated 1 time (1X; 8 pens), 2 times (2X; 8 pens), or 3 or 4 times (3/4X; 8 pens). Arrival BW was not different among BRDX groups $(P$ $=0.17$ ); however, BRDX during the receiving period decreased performance, resulting in BW of $324,316,285$, and $260 \mathrm{~kg}$ for $0 \mathrm{X}, 1 \mathrm{X}, 2 \mathrm{X}$, and $3 / 4 \mathrm{X}$, respectively, at the start of finishing $(P<0.001)$. Ultrasound estimates, BW, and visual appraisal were used to target a common body composition (average days on feed $=182$ ). With increasing BRDX, days on feed increased linearly $(P=0.002)$, whereas HCW, DP, rib eye area, QG, and unconsolidated lungs decreased linearly $(P \leq 0.03)$. These results suggest that with additional days on feed, calves treated multiple times for $\mathrm{BRD}$ are able to reach similar compositional endpoints as their untreated cohorts; however, it may not be possible for these calves to reach the same QG and carcass yield.
\end{abstract}

Key words: bovine respiratory disease, carcass characteristics, finishing performance, high-risk calf, feedlot economics

\section{INTRODUCTION}

Bovine respiratory disease (BRD) is a complex illness and a multitude of stressors, viruses, and bacterial pathogens can potentially contribute to its onset (Duff and

${ }^{1}$ Corresponding author: the.blake.wilson@okstate.edu
Galyean, 2007). Development of clinical BRD frequently occurs via a primary infection with one or more respiratory viruses. The initial viral infection combined with a compromised immune system then allows for the rapid colonization of bacteria within the lungs (Hodgins et al., 2002). The BRD complex accounts for the majority of morbidity, mortality, decreased production, and economic losses in feedlots.

Woolums et al. (2005) implicated BRD as the leading cause of morbidity and mortality in 561 feedlots in 21 states. Morbidity attributed to BRD can account for approximately $75 \%$ of total morbidity, and mortality attributed to BRD accounts for 36 to $80 \%$ of total mortality in feedlot cattle (Vogel and Parrott, 1994; Edwards, 1996; Smith, 1998; Chirase and Greene, 2001). In a 2011 survey, NAHMS (2013) stated almost all feedlots (96.9\%) had cattle that were affected by BRD and that BRD was the most common illness in feedlots, affecting $16.2 \%$ of cattle placed on feed. Economic losses from BRD result from antimicrobial treatments, increased labor, mortalities, chronic BRD cases, and decreased performance of calves treated for BRD. Powell (2013) estimated annual economic losses resulting from BRD to be in excess of $\$ 2$ billion.

In an experiment with a slightly different treatment structure, Holland et al. (2010) examined the effects of previous BRD incidence in heifers. The authors suggested that when calves were slaughtered at common endpoints, animals requiring multiple antimicrobial treatments for BRD were able to produce carcasses with similar value to untreated animals given additional days on feed (DOF). The objective of this experiment was to evaluate the effect of BRD incidence during the receiving period on subsequent finishing performance, efficiency, carcass characteristics, and lung scores of steers.

\section{MATERIALS AND METHODS}

\section{Cattle Description and Initial Processing}

All procedures for the present experiment were approved by the Oklahoma State University Institutional Animal Care and Use Committee (Animal Care and Use Protocol AG-12-11). The calves used in this experiment $(\mathrm{n}=$ 
$174)$ were part of a larger initial cohort $(\mathrm{n}=516$; BW at arrival $=217 \pm 20 \mathrm{~kg}$ ) of calves. Calves were purchased over the course of $1 \mathrm{wk}$ in September at livestock auctions throughout Oklahoma and transported (average distance $=135 \mathrm{~km}$ ) to the Willard Sparks Beef Research Center (WSBRC) at Oklahoma State University. Upon arrival at the feed yard, calves were individually weighed and a uniquely numbered ear tag was placed in the left ear of each calf. Calves were given ad libitum access to prairie hay and water, and allowed to rest 24 to $48 \mathrm{~h}$ before initial processing. Initial processing consisted of vaccination for infectious bovine rhinotracheitis virus, bovine viral diarrhea virus types 1 and 2, parainfluenza 3 virus, and bovine respiratory syncytial virus; vaccination for Clostridium chauvoei, Clostridium septicum, Clostridium novyi, Clostridium sordellii, and Clostridium perfringens types C and $\mathrm{D}$; and treatment for the control of internal and external parasites (Ivomec Plus; Merial, Duluth, GA). Bulls (n $=355$ ) were surgically castrated by incising the scrotum with a Newberry castrating knife followed by emasculation by a single individual, and calves with horns $(\mathrm{n}=57)$ had their horns tipped with a Keystone dehorner.

Before the initiation of this experiment, 126 of the calves were enrolled in a receiving experiment $(87 \pm 3 \mathrm{~d})$ evaluating ancillary therapy (ANC) use in calves receiving an antimicrobial for BRD. The remaining 48 steers never met antimicrobial treatment criteria for BRD, never received an antimicrobial, and thus were not allocated to the ANC receiving experiment. These untreated calves were fed, housed, and managed identically to those calves on the ANC receiving experiment. For this experiment, calves were grouped by previous experimental ANC and the number of times treated for BRD (BRDX) and then randomly allocated to finishing pens so that only a single ANC and BRDX were represented within a pen. This was done to allow for the analysis of interactions between BRDX and previous ANC experimental treatments. Calves selected for this experiment were representative of the initial experimental population and were subsampled from the experimental population based on BW. Additional information about the cattle used in the current experiment as well as processing, management, and feeding practices that occurred during the receiving period are available in a manuscript by Wilson et al. (2015).

\section{Receiving Period BRD Assessment, Antimicrobial Administration, and BRD Incidence}

During the receiving period, calves were visually monitored twice daily at 0700 and $1300 \mathrm{~h}$ by veterinarian-trained evaluators for clinical signs of BRD. The visual evaluation employed subjective criteria based on the DART system (Zoetis, Florham Park, NJ) with some modifications as described by Step et al. (2008). The subjective criteria used for pulling calves consisted of depression, abnormal appetite, and respiratory signs and are described in great- er detail by Wilson et al. (2015). Each calf was assigned a severity score from 0 to 4 based on the clinical signs exhibited and the severity of those observed signs. A clinically normal appearing calf was assigned a severity score of 0 , whereas a 1 was assigned to a calf with mild clinical signs, a 2 would have been assigned to a calf with moderate clinical signs, a 3 was assigned to a calf with severe clinical signs, and 4 was assigned to a moribund calf. For a calf to be assigned a score of 4 , the calf had to be unable to rise; require assistance to rise; or have extreme difficulty standing, walking, or breathing. In extreme cases, an Institutional Animal Care and Use Committee-approved euthanasia procedure was used if euthanasia was deemed necessary by the attending veterinarian.

The objective criteria used to determine whether antimicrobial treatment was necessary was rectal temperature. Any calf that was identified with a severity score of 1 or 2 and had a rectal temperature of $40^{\circ} \mathrm{C}$ or greater received an antimicrobial according to label instructions. If a calf was identified with a severity score of 1 or 2 and had a rectal temperature of less than $40^{\circ} \mathrm{C}$, no antimicrobial treatment was administered. Any calf with severe clinical signs (severity score $=3$ or 4 ) received an antimicrobial according to label instructions regardless of rectal temperature. A maximum of 4 antimicrobial treatments were administered during the experiment. Antimicrobials administered included gamithromycin, $150 \mathrm{mg} / \mathrm{mL}$ (Zactran; Merial); florfenicol, $300 \mathrm{mg} / \mathrm{mL}$ (Nuflor; Intervet/Schering-Plough, De Soto, KS); and ceftiofur crystalline free acid, $200 \mathrm{mg} /$ mL (Excede; Pfizer, New York, NY). All antimicrobials were administered subcutaneously per manufacturer's label directions following the National Cattlemen's Beef Association Beef Quality Assurance Guidelines (NCBA, 2001). Additional information concerning the administration of those antimicrobials can be found in the study by Wilson et al. (2015).

Gross postmortem examinations were performed on all mortalities by veterinarian-trained personnel to determine cause of death. All mortalities $(\mathrm{n}=68)$ that occurred during the receiving period were attributed to BRD. Full postmortem necropsies were performed on 3 random mortalities by the Oklahoma Animal Disease Diagnostic Laboratory. Bacterial and viral pathogens identified in the necropsy reports included Mannheimia haemolytica, Mycoplasma bovis, Pasteurella multocida, bovine viral diarrhea virus, and bovine coronavirus.

\section{Finishing Phase Cattle Management and Diet}

After the receiving period, calves remained in their home pens and received ad libitum access to a common receiving diet (Table 1) and water for 2 to 3 additional weeks. After this additional period (average total receiving/backgrounding DOF $=87$ ), a subset of 174 calves were allocated to the finishing experiment. For the finishing experiment, calves were allocated by previous experimental ANC and BRDX so that only a single ANC and BRDX 
were represented within a pen. The BRDX experimental groups included never treated for BRD $(\mathbf{0 X})$ and treated 1 time $(\mathbf{1 X}), 2$ times $(\mathbf{2 X})$, or 3 or 4 times $(\mathbf{3} / \mathbf{4 X})$. Experimental BRDX groups were replicated 8 times $(8$ pens per BRDX), and pens contained up to 6 steers. For the $3 / 4 \mathrm{X}$ experimental treatment, some pens contained less than 6 head ( 3 pens contained 3 head, 4 pens contained 4 head, and 1 pen contained 5 head). This was due to the remaining pool of $3 / 4 \mathrm{X}$ calves being insufficient for each pen to contain 6 head when the experiment was initiated.

Before allocation to finishing pens, all steers were implanted with $200 \mathrm{mg}$ of trenbolone acetate and $40 \mathrm{mg}$ of estradiol (Revalor XS; Merck Animal Health, Summit, $\mathrm{NJ}$ ). The protocol for this experiment was to slaughter all calves at a common compositional endpoint with an emphasis on achieving a 12th-rib fat thickness of $1.27 \mathrm{~cm}$ regardless of DOF, while still maintaining the integrity of the pen and shipping the cattle in truck load lots. This

Table 1. Composition of the common receiving diet ${ }^{1}$

\begin{tabular}{|c|c|}
\hline Item ${ }^{1}$ & Value \\
\hline \multicolumn{2}{|l|}{ Ingredient, \% } \\
\hline Sweet Bran ${ }^{2}$ & 48.8 \\
\hline Grain sorghum hay & 30.0 \\
\hline Dry-rolled corn & 15.0 \\
\hline Dry supplement B-273³ & 5.2 \\
\hline \multicolumn{2}{|l|}{ Nutrient composition ${ }^{4}$} \\
\hline $\mathrm{NE}_{\mathrm{m}}, \mathrm{Mcal} / \mathrm{kg}$ & 1.69 \\
\hline $\mathrm{NE}_{\mathrm{q}}, \mathrm{Mcal} / \mathrm{kg}$ & 1.07 \\
\hline TDN, \% & 71.60 \\
\hline $\mathrm{CP}, \%$ & 17.40 \\
\hline Crude fat, \% & 1.90 \\
\hline NDF, $\%$ & 39.90 \\
\hline ADF, \% & 21.40 \\
\hline Calcium, \% & 0.68 \\
\hline Phosphorus, \% & 0.67 \\
\hline Magnesium, \% & 0.36 \\
\hline Potassium, \% & 1.15 \\
\hline Sulfur, $\%$ & 0.27 \\
\hline Sodium, \% & 0.13 \\
\hline
\end{tabular}

${ }^{1}$ All values are presented on a DM basis.

${ }^{2}$ Corn gluten feed product (Cargill, Dalhart, TX).

${ }^{3}$ Dry supplement B-273 was formulated to contain (\% DM basis) $38.46 \%$ ground corn, $30.36 \%$ limestone, $21.04 \%$ wheat middlings, $6.92 \%$ urea, $1.03 \%$ magnesium oxide, $0.618 \%$ zinc sulfate, $0.38 \%$ salt, $0.119 \%$ copper sulfate, $0.116 \%$ manganese oxide, $0.05 \%$ selenium premix (contained $0.6 \% \mathrm{Se}), 0.311 \%$ vitamin A $(30,000 \mathrm{lU} / \mathrm{g})$, $0.085 \%$ vitamin E (500 IU/g), 0.317\% Rumensin 90 (Elanco Animal Health, Indianapolis, IN), and 0.195\% Tylan 40 (Elanco Animal Health).

${ }^{4}$ Feed samples were analyzed for nutrient composition and energy values were calculated from the analyzed composition by an independent laboratory (Servi-Tech Laboratories, Dodge City, KS). was accomplished through the use of ultrasound estimates of 12th-rib fat thickness on d 91 and 138, BW, and visual appraisal. Calves were slaughtered in 2 groups during May and June $(\mathrm{DOF}=166$ or 197). For the last $28 \mathrm{DOF}$, all steers were fed ractopamine hydrochloride (Optaflexx 45;

Table 2. Composition of the common finishing $\operatorname{diet}^{1}$

\begin{tabular}{|c|c|}
\hline Item $^{1}$ & Value \\
\hline \multicolumn{2}{|l|}{ Ingredient, \% } \\
\hline Dry-rolled corn & 48.14 \\
\hline Sweet Bran² & 15.00 \\
\hline Dried distillers grains plus solubles & 15.00 \\
\hline Prairie hay & 9.00 \\
\hline Liquid supplement ${ }^{3}$ & 6.54 \\
\hline Dry supplement B-273 & 3.12 \\
\hline Dry supplement B-2835 & 3.20 \\
\hline \multicolumn{2}{|l|}{ Nutrient composition ${ }^{6}$} \\
\hline $\mathrm{NE}_{\mathrm{m}}, \mathrm{Mcal} / \mathrm{kg}$ & 2.23 \\
\hline $\mathrm{NE}_{\mathrm{g}}, \mathrm{Mcal} / \mathrm{kg}$ & 1.54 \\
\hline TDÑ, \% & 89.55 \\
\hline $\mathrm{CP}, \%$ & 18.85 \\
\hline Crude fat, \% & 5.00 \\
\hline NDF, $\%$ & 22.35 \\
\hline ADF, $\%$ & 10.40 \\
\hline Calcium, \% & 0.96 \\
\hline Phosphorus, \% & 0.52 \\
\hline Magnesium, \% & 0.28 \\
\hline Potassium, \% & 1.03 \\
\hline Sulfur, \% & 0.31 \\
\hline Sodium, \% & 0.13 \\
\hline
\end{tabular}

${ }^{1}$ All values are presented on a DM basis.

${ }^{2}$ Corn gluten feed product (Cargill, Dalhart, TX).

3Synergy 19-14 (Westway Feed Products, New Orleans, LA).

${ }^{4}$ Dry supplement B-273 was formulated to contain (\% DM basis) $38.46 \%$ ground corn, $30.36 \%$ limestone, $21.04 \%$ wheat middlings, $6.92 \%$ urea, $1.03 \%$ magnesium oxide, $0.618 \%$ zinc sulfate, $0.38 \%$ salt, $0.119 \%$ copper sulfate, $0.116 \%$ manganese oxide, $0.05 \%$ selenium premix (contained $0.6 \% \mathrm{Se}), 0.311 \%$ vitamin A $(30,000 \mathrm{lU} / \mathrm{g})$, $0.085 \%$ vitamin E (500 IU/g), 0.317\% Rumensin 90 (Elanco Animal Health, Indianapolis, IN), and $0.195 \%$ Tylan 40 (Elanco Animal Health).

${ }^{5}$ Dry supplement B-283 was formulated to contain (\% DM basis) $40.47 \%$ limestone, $36.26 \%$ ground corn, $19.73 \%$ wheat middlings, $2.47 \%$ salt, $0.312 \%$ zinc sulfate, $0.071 \%$ copper sulfate, $0.064 \%$ manganese oxide, $0.029 \%$ selenium premix (contained $0.6 \% \mathrm{Se}$ ), $0.202 \%$ vitamin A $(30,000 \mathrm{lU} / \mathrm{g}), 0.056 \%$ vitamin E (500 IU/g), 0.207\% Rumensin 90 (Elanco Animal Health, Indianapolis, IN), and $0.127 \%$ Tylan 40 (Elanco Animal Health).

${ }^{6}$ Feed samples were analyzed for nutrient composition and energy values were calculated from the analyzed composition by an independent laboratory. (Servi-Tech Laboratories, Dodge City, KS). 
Elanco Animal Health, Indianapolis, IN) at $300.75 \mathrm{mg} /$ steer per d.

Finishing pens were $4.57 \times 15.24 \mathrm{~m}$ in area (minimum of $11.61 \mathrm{~m}^{2} /$ steer) with a 4.57 -m-long concrete bunk at the front of the pen. The pens contained a $4.57 \times 4.42 \mathrm{~m}$ concrete pad, with the remainder of the pen being soil surfaced. The pens were under partial cover, with the bunk and pad being covered by an overhang. A 76-L concrete

Table 3. Effect of $0,1,2$, or 3 or 4 antimicrobial treatments for bovine respiratory disease (BRD) during the receiving period on subsequent finishing performance and efficiency of steers

\begin{tabular}{|c|c|c|c|c|c|c|c|c|}
\hline \multirow[b]{2}{*}{ Item } & \multicolumn{4}{|c|}{ Treatments administered $^{1}$} & \multirow[b]{2}{*}{$\begin{array}{l}\text { Pooled } \\
\text { SEM }\end{array}$} & \multicolumn{3}{|c|}{$P$-value ${ }^{2}$} \\
\hline & $\mathbf{0 X}$ & $1 X$ & $2 X$ & $3 / 4 X$ & & $\begin{array}{l}\text { Overall } \\
P \text {-value }\end{array}$ & $\begin{array}{l}\text { Linear } \\
\text { contrast }\end{array}$ & $\begin{array}{c}\text { Quadratic } \\
\text { contrast }\end{array}$ \\
\hline $\begin{array}{l}\text { Days on } \mathrm{feed}_{,}{ }^{3} \mathrm{~d} \\
\text { Animal } \mathrm{BW},{ }^{4} \mathrm{~kg}\end{array}$ & \multicolumn{7}{|c|}{ Animal BW, ${ }^{4} \mathrm{~kg}$} & 1.00 \\
\hline d 0 & 324 & 316 & 285 & 260 & 5.98 & $<0.001$ & $<0.001$ & 0.18 \\
\hline d 45 & 402 & 395 & 364 & 336 & 6.71 & $<0.001$ & $<0.001$ & 0.12 \\
\hline d 91 & 459 & 456 & 425 & 408 & 7.20 & $<0.001$ & $<0.001$ & 0.34 \\
\hline d 138 & 517 & 522 & 486 & 480 & 6.65 & $<0.001$ & $<0.001$ & 0.41 \\
\hline Final & 568 & 572 & 560 & 552 & 4.89 & 0.04 & 0.01 & 0.25 \\
\hline \multicolumn{9}{|l|}{$A D G,{ }^{5} \mathrm{~kg}$} \\
\hline d 0 to 45 & 1.74 & 1.76 & 1.78 & 1.70 & 0.05 & 0.68 & 0.66 & 0.29 \\
\hline d 46 to 91 & 1.23 & 1.33 & 1.31 & 1.53 & 0.05 & 0.005 & 0.002 & 0.28 \\
\hline d 92 to 138 & 1.23 & 1.41 & 1.30 & 1.53 & 0.04 & $<0.001$ & $<0.001$ & 0.53 \\
\hline d 139 to final & 1.50 & 1.60 & 1.39 & 1.46 & 0.09 & 0.40 & 0.40 & 0.85 \\
\hline d 0 to final & 1.41 & 1.51 & 1.43 & 1.54 & 0.03 & 0.02 & 0.05 & 0.83 \\
\hline \multicolumn{9}{|l|}{$\mathrm{DMI},{ }^{6} \mathrm{~kg}$} \\
\hline d 0 to 45 & 8.94 & 8.95 & 8.60 & 8.35 & 0.15 & 0.02 & 0.004 & 0.38 \\
\hline d 46 to 91 & 9.83 & 10.0 & 9.70 & 10.0 & 0.26 & 0.78 & 0.86 & 0.85 \\
\hline d 92 to 138 & 9.81 & 10.1 & 9.68 & 10.5 & 0.24 & 0.07 & 0.12 & 0.27 \\
\hline d 139 to final & 9.74 & 10.1 & 9.89 & 10.3 & 0.26 & 0.49 & 0.26 & 0.97 \\
\hline d 0 to final & 9.56 & 9.78 & 9.47 & 9.75 & 0.18 & 0.57 & 0.75 & 0.86 \\
\hline \multicolumn{9}{|l|}{$\mathrm{DMI}^{7} \%$ of BW } \\
\hline d 0 to 45 & 2.46 & 2.52 & 2.65 & 2.80 & 0.03 & $<0.001$ & $<0.001$ & 0.16 \\
\hline d 46 to 91 & 2.29 & 2.36 & 2.46 & 2.69 & 0.06 & $<0.001$ & $<0.001$ & 0.18 \\
\hline d 92 to $138^{8}$ & 2.01 & 2.07 & 2.13 & 2.37 & 0.05 & $<0.001$ & $<0.001$ & 0.06 \\
\hline d 139 to final $^{9}$ & 1.80 & 1.85 & 1.89 & 1.99 & 0.04 & 0.04 & 0.005 & 0.66 \\
\hline d 0 to final & 2.14 & 2.21 & 2.24 & 2.40 & 0.04 & $<0.001$ & $<0.001$ & 0.17 \\
\hline \multicolumn{9}{|l|}{$G: F^{10}$} \\
\hline d 0 to 45 & 0.194 & 0.196 & 0.207 & 0.204 & $<0.01$ & 0.20 & 0.06 & 0.64 \\
\hline d 46 to 91 & 0.126 & 0.133 & 0.136 & 0.154 & 0.01 & 0.01 & 0.002 & 0.36 \\
\hline d 92 to 138 & 0.126 & 0.139 & 0.135 & 0.146 & $<0.01$ & 0.05 & 0.01 & 0.83 \\
\hline d 139 to final & 0.155 & 0.158 & 0.140 & 0.142 & 0.01 & 0.26 & 0.11 & 0.94 \\
\hline d 0 to final & 0.148 & 0.154 & 0.151 & 0.158 & $<0.01$ & 0.22 & 0.09 & 0.93 \\
\hline
\end{tabular}

${ }^{1}$ Number of antimicrobial treatments administered for BRD (BRDX) during the receiving period: never treated for BRD (OX), treated once for BRD (1X), treated twice for BRD (2X), or treated 3 or 4 times for BRD $(3 / 4 X)$.

${ }^{2} P$-values are included for the overall $F$-test and the linear and quadratic contrast for the number of times treated for BRD.

${ }^{3}$ Average of days on feed (DOF) for all pens within an experimental treatment.

${ }^{4}$ Treatment BW was the BW in kilograms with a calculated $4 \%$ shrink.

${ }^{5}$ Treatment ADG was calculated from the shrunk (4\%) BW in kilograms and DOF between the time periods.

${ }^{6}$ Treatment DMI was calculated by taking DMI in kilograms for a pen for the period presented divided by the actual number of head days within each pen.

${ }^{7}(\mathrm{DMl} /$ average BW for the time period) $\times 100$.

${ }^{8}$ There was a BRDX $\times$ ancillary therapy interaction $(P=0.01)$ for $\mathrm{d} 92$ to $138 \mathrm{DMI}$ as a percentage of BW.

${ }^{9}$ There was a BRDX $\times$ ancillary therapy interaction $(P=0.03)$ for $\mathrm{d} 139$ to final DMl as a percentage of BW.

${ }^{10}$ Treatment G:F was calculated by taking the pen ADG in kilograms divided by the pen average DMI in kilograms for the time periods. 
water tank (Model J 360-F; Johnson Concrete, Hastings, $\mathrm{NE}$ ) was shared between 2 pens and was cleaned 3 times/ wk throughout the experiment.

The common finishing diet was formulated to meet or exceed NRC (2000) nutrient requirements (Table 2). Adaptation to the finishing diet was accomplished using a 2-ration blend method where the percentage of finishing diet delivered was increased by approximately $4.6 \%$ on a DM basis and the percentage of receiving diet (Table 1) delivered was decreased by approximately $4.6 \%$ on a DM basis each day until only the finishing diet was being fed. Following adaptation, the finishing diet was fed to all cattle twice daily at 0700 and $1300 \mathrm{~h}$ to the nearest $0.45 \mathrm{~kg}$ of that day's feed call. Diet samples were collected once a week and were dried in a forced-air oven to determine DM and then composited gravimetrically and analyzed at a commercial laboratory (Servi-Tech Inc., Dodge City, KS) for nutrient composition (Table 2). Additional information concerning feeding practices, sampling, and diet analysis procedures is reported by Wilson et al. (2015).

\section{Finishing Phase Data Collection, Calculations, and Statistical Analysis}

Unshrunk BW were obtained at the time of allocation to finishing pens and at approximately 45-d intervals thereafter. All BW were shrunk 4\%. Individual BW and ADG values were averaged within a pen to obtain pen mean BW and ADG. Ultrasound estimates of rib eye area (REA), 12th-rib fat thickness, and intramuscular fat were taken on d 91 and 138 by a certified ultrasound technician (Ultrasound Technologies, Fletcher, OK). Carcass data, liver scores, and lung consolidation and adhesion scores were obtained by trained personnel from the West Texas A\&M University Beef Carcass Research Center at slaughter. Liver scores and lung consolidation and adhesion scores were

Table 4. Effect of $0,1,2$, or 3 or 4 antimicrobial treatments for bovine respiratory disease (BRD) during the receiving period on subsequent carcass characteristics of steers

\begin{tabular}{|c|c|c|c|c|c|c|c|c|}
\hline \multirow[b]{2}{*}{ Variable } & \multicolumn{4}{|c|}{ Treatments administered $^{1}$} & \multirow[b]{2}{*}{$\begin{array}{c}\text { Pooled } \\
\text { SEM }\end{array}$} & \multicolumn{3}{|c|}{$P$-value ${ }^{2}$} \\
\hline & $0 x$ & $1 X$ & $2 X$ & $3 / 4 X$ & & $\begin{array}{l}\text { Overall } \\
P \text {-value }\end{array}$ & $\begin{array}{l}\text { Linear } \\
\text { contrast }\end{array}$ & $\begin{array}{c}\text { Quadratic } \\
\text { contrast }\end{array}$ \\
\hline \multicolumn{9}{|l|}{ Ultrasound estimates ${ }^{3}$} \\
\hline d $91 \mathrm{REA},{ }^{4} \mathrm{~cm}^{2}$ & 81.3 & 84.1 & 77.0 & 73.7 & 1.49 & $<0.001$ & $<0.001$ & 0.05 \\
\hline d 91 12th-rib fat, cm & 0.82 & 0.82 & 0.81 & 0.72 & 0.04 & 0.21 & 0.08 & 0.25 \\
\hline d 91 IMF & 4.55 & 4.29 & 4.42 & 4.04 & 0.15 & 0.10 & 0.04 & 0.70 \\
\hline d 138 REA, $\mathrm{cm}^{2}$ & 88.9 & 89.6 & 84.6 & 83.8 & 1.71 & 0.05 & 0.01 & 0.65 \\
\hline d 138 12th-rib fat, cm & 0.94 & 0.93 & 0.91 & 0.91 & 0.05 & 0.95 & 0.60 & 0.99 \\
\hline d $138 \mathrm{IMF}$ & 4.60 & 4.28 & 4.49 & 4.24 & 0.15 & 0.32 & 0.22 & 0.83 \\
\hline $\mathrm{HCW}, \mathrm{kg}$ & 372 & 369 & 360 & 353 & 3.66 & 0.004 & $<0.001$ & 0.63 \\
\hline DP & 65.5 & 64.6 & 64.2 & 64.0 & 0.27 & 0.003 & $<0.001$ & 0.23 \\
\hline $\mathrm{REA}, \mathrm{cm}^{2}$ & 91.8 & 93.9 & 90.8 & 87.3 & 1.56 & 0.05 & 0.03 & 0.09 \\
\hline REA, ${ }^{5} \%$ of $\mathrm{HCW}$ & 24.7 & 25.4 & 25.3 & 24.7 & 0.44 & 0.52 & 0.97 & 0.15 \\
\hline 12th-rib fat, cm & 1.33 & 1.28 & 1.36 & 1.40 & 0.09 & 0.83 & 0.49 & 0.63 \\
\hline $\mathrm{KPH}$ fat, $\%$ & 2.17 & 2.01 & 2.08 & 2.00 & 0.06 & 0.26 & 0.16 & 0.55 \\
\hline Marbling score 6 & 451 & 428 & 426 & 406 & 16.7 & 0.29 & 0.10 & 0.91 \\
\hline Prime and choice, ${ }^{7} \%$ & 70.3 & 56.5 & 60.2 & 36.2 & 9.15 & 0.06 & 0.03 & 0.54 \\
\hline YG & 2.81 & 2.60 & 2.75 & 2.91 & 0.16 & 0.59 & 0.53 & 0.26 \\
\hline Liver score $^{8}$ & 0.67 & 0.23 & 0.63 & 0.46 & 0.27 & 0.65 & 0.86 & 0.61 \\
\hline
\end{tabular}

${ }^{1}$ Number of antimicrobial treatments administered for BRD (BRDX) during the receiving period: never treated for BRD (OX), treated once for BRD (1X), treated twice for BRD (2X), or treated 3 or 4 times for BRD (3/4X).

${ }^{2} P$-values are included for the overall $F$-test and the linear and quadratic contrast for the number of times treated for BRD.

${ }^{3}$ Ultrasound estimates of rib eye area (REA), 12th-rib fat thickness, and intramuscular fat (IMF) were taken on d 91 and 138 by a certified ultrasound technician (Ultrasound Technologies, Fletcher, OK).

${ }^{4}$ There was a tendency $(P=0.08)$ for a BRDX $\times$ ancillary therapy interaction for d-91 REA.

${ }^{5}(\mathrm{REA} / \mathrm{HCW}) \times 100$.

${ }^{6}$ Marbling scores: $400=$ Small ${ }^{00}, 500=$ Modest $^{00}$. There was a BRDX $\times$ ancillary therapy interaction $(P=0.03)$ for marbling score.

${ }^{7}$ Pecentage of calves grading USDA Prime and Choice within each pen.

${ }^{8}$ Liver Score: $0=$ no abscesses, $1=\mathrm{A}-, 2=\mathrm{A}, 3=\mathrm{A}+, 4=$ telangiectasis, $5=$ distoma (fluke damage), and $6=$ fecal contamination. 
Table 5. Effect of $0,1,2$, or 3 or 4 antimicrobial treatments for bovine respiratory disease (BRD) during the receiving period on lung consolidation and lung adhesion scores of steers ${ }^{1}$

\begin{tabular}{|c|c|c|c|c|c|c|c|c|}
\hline \multirow[b]{2}{*}{ Variable } & \multicolumn{4}{|c|}{ Treatments administered ${ }^{2}$} & \multirow[b]{2}{*}{$\begin{array}{l}\text { Pooled } \\
\text { SEM }\end{array}$} & \multicolumn{3}{|c|}{$P$-value ${ }^{3}$} \\
\hline & $0 x$ & $1 X$ & $2 x$ & $3 / 4 X$ & & $\begin{array}{l}\text { Overall } \\
P \text {-value }\end{array}$ & $\begin{array}{l}\text { Linear } \\
\text { contrast }\end{array}$ & $\begin{array}{c}\text { Quadratic } \\
\text { contrast }\end{array}$ \\
\hline \multicolumn{9}{|c|}{ Lung consolidation ${ }^{4}$} \\
\hline Score $0, \%$ & 80.8 & 62.5 & 45.8 & 42.7 & 8.93 & 0.02 & $<0.01$ & 0.40 \\
\hline Score $1, \%$ & 12.9 & 25 & 10.4 & 27.5 & 9.53 & 0.50 & 0.50 & 0.79 \\
\hline Score 2, \% & 2.08 & 10.4 & 35.4 & 19.6 & 7.82 & 0.03 & 0.04 & 0.13 \\
\hline Score 3, \% & 4.17 & 2.08 & 8.33 & 10.2 & 3.92 & 0.45 & 0.18 & 0.62 \\
\hline \multicolumn{9}{|c|}{ Lung adhesion ${ }^{5}$} \\
\hline Score $0, \%$ & 48.8 & 35.4 & 57.3 & 40.4 & 8.78 & 0.33 & 0.94 & 0.84 \\
\hline Score $1, \%$ & 34.6 & 33.3 & 18.8 & 36.3 & 7.66 & 0.36 & 0.78 & 0.23 \\
\hline Score $2, \%$ & 16.7 & 31.3 & 24.0 & 23.3 & 6.67 & 0.50 & 0.67 & 0.26 \\
\hline
\end{tabular}

${ }^{1}$ Lung scores were obtained by trained personnel from West Texas A\&M University Beef Carcass Research Center. ${ }^{2}$ Number of antimicrobial treatments administered for BRD (BRDX) during the receiving period: never treated for BRD (0X), treated once for BRD (1X), treated twice for BRD $(2 X)$, or treated 3 or 4 times for BRD (3/4X).

${ }^{3} P$-values are included for the overall $F$-test and the linear and quadratic contrast for the number of times treated for BRD.

${ }^{4}$ Lung consolidation: $0=$ clinically normal, healthy lung with $<5 \%$ consolidation of lung tissue; $1= \pm 5 \%$ consolidation of lung tissue or mycoplasma-like lesion; $2=>5 \%$ but $<50 \%$ consolidation of lung tissue, missing lung, or mycoplasma-like lesion; 3 $=>50 \%$ consolidation of lung tissue, missing lung, or mycoplasma-like lesion.

${ }^{5}$ Lung adhesion: 0 = clinically normal, healthy lung; 1 = minor threadlike fibrous adhesion; 2 = extensive fibrous adhesion.

then converted to a numeric scale. Liver scores consisted of $0=$ no liver abscesses, $1=\mathrm{A}-$ liver, $2=\mathrm{A}$ liver, $3=$ A + liver, $4=$ telangiectasis, $5=$ distoma (fluke damage), and $6=$ fecal contamination. Lung consolidation scores consisted of $0=$ clinically normal, healthy lung with $<5 \%$ consolidation of lung tissue; $1= \pm 5 \%$ consolidation of lung tissue or mycoplasma-like lesion; $2=>5 \%$ but $<50 \%$ consolidation of lung tissue, missing lung, or mycoplasmalike lesion; and $3=>50 \%$ consolidation of lung tissue, missing lung, or mycoplasma-like lesion. Lung adhesion scores consisted of $0=$ clinically normal, healthy lung; 1 $=$ minor threadlike fibrous adhesion; and $2=$ extensive fibrous adhesion.

All continuous animal performance and carcass characteristic data were analyzed using the MIXED procedure of SAS 9.4 (SAS Institute Inc., Cary, NC) with pen serving as the experimental unit. Nonparametric carcass data, liver scores, and lung consolidation and adhesion scores were analyzed as binomially distributed data using the GLIMMIX procedure of SAS with the mixed model notated above. Before analysis for the main effect of BRDX, analysis for the interaction of BRDX and previous ANC experimental treatment was completed. Any interactions that existed between BRDX and previous ANC are notated in Tables 3, 4, and 5. Only 3 significant interactions were observed for all of the variables analyzed. Orthogonal contrasts were then performed for the linear and quadratic effects of BRDX. Contrasts were not considered unless the overall model was significant $(P \leq 0.05)$ or tended to be significant $(0.05<P \leq 0.10)$. Data were analyzed with mortalities (4; 3 digestive and 1 BRD) included in the analysis (deads in). One calf from the $2 \mathrm{X}$ group and 3 calves from the $3 / 4 \mathrm{X}$ group died during the experiment. Because of circumstances beyond our control, the calves slaughtered at 197 DOF experienced a longer chill time at the packing facility before grading. Due to calves being slaughtered at varying DOF and there being a difference in chill time before grading between the slaughter groups,

Table 6. Actual slaughter grid premiums and discounts ${ }^{1}$

\begin{tabular}{lc} 
Variable & $\$ / 100 \mathbf{~ k g ~}(\$ / 100$ pounds) \\
\hline Base carcass price & $440.64(199.87)$ \\
QG premiums and discounts & $-47.07(-21.35)$ \\
Standard & $-19.51(-8.85)$ \\
Select & $0.00(0.00)$ \\
Choice & $23.70(10.75)$ \\
Premium choice & $36.93(16.75)$ \\
Prime & \\
YG premiums and discounts & $14.33(6.50)$ \\
YG 1 & $5.51(2.50)$ \\
YG 2 & $0.00(0.00)$ \\
YG 3 & $-17.64(-8.00)$ \\
YG 4 &
\end{tabular}

${ }^{1}$ All prices are reported as $\$ / 100 \mathrm{~kg}$ of $\mathrm{HCW}$, with $\$ / 100$ pounds of HCW in parentheses. Only known premiums and discounts are included. 
Table 7. Effect of $0,1,2$, or 3 or 4 antimicrobial treatments for bovine respiratory disease (BRD) during the receiving period on carcass value at slaughter and feedlot economics ${ }^{1}$

\begin{tabular}{|c|c|c|c|c|c|c|c|c|}
\hline \multirow[b]{2}{*}{ Variable } & \multicolumn{4}{|c|}{ Treatments administered $^{2}$} & \multirow[b]{2}{*}{$\begin{array}{l}\text { Pooled } \\
\text { SEM }\end{array}$} & \multicolumn{3}{|c|}{$P$-value ${ }^{3}$} \\
\hline & oX & $1 X$ & $2 X$ & $3 / 4 X$ & & $\begin{array}{l}\text { Overall } \\
P \text {-value }\end{array}$ & $\begin{array}{l}\text { Linear } \\
\text { contrast }\end{array}$ & $\begin{array}{l}\text { Quadratic } \\
\text { contrast }\end{array}$ \\
\hline Final shrunk BW, kg & 568 & 572 & 560 & 552 & 4.89 & 0.04 & 0.01 & 0.25 \\
\hline DP & 65.5 & 64.6 & 64.2 & 64.0 & 0.27 & 0.003 & $<0.001$ & 0.23 \\
\hline $\mathrm{HCW}, \mathrm{kg}$ & 372 & 369 & 360 & 353 & 3.66 & 0.004 & $<0.001$ & 0.63 \\
\hline QG adjustment, ${ }^{4} \$ / 100 \mathrm{~kg}$ & -1.97 & -8.19 & -0.65 & -5.79 & 3.23 & 0.37 & 0.79 & 0.87 \\
\hline YG adjustment, ${ }^{5} \$ / 100 \mathrm{~kg}$ & 3.17 & 4.59 & 3.17 & 1.65 & 1.36 & 0.51 & 0.33 & 0.29 \\
\hline Actual carcass price, ${ }^{6} \$ / 100 \mathrm{~kg}$ & 441.83 & 437.04 & 443.16 & 436.48 & 2.80 & 0.25 & 0.43 & 0.74 \\
\hline Total carcass value, ${ }^{7} \$$ & $1,643.80$ & $1,612.67$ & $1,589.01$ & $1,540.46$ & 20.6 & 0.01 & 0.001 & 0.68 \\
\hline $\begin{array}{l}\text { Carcass value difference from previous } \\
\text { BRDX, \$ }\end{array}$ & 0.00 & -31.13 & -23.66 & -48.55 & 18.0 & 0.31 & 0.10 & 0.86 \\
\hline Carcass value difference from $0 X, \$$ & 0.00 & -31.13 & -54.79 & -103.34 & 18.0 & 0.003 & $<0.001$ & 0.63 \\
\hline Antimicrobial treatment cost, ${ }^{8} \$$ & 0.00 & -14.40 & -29.60 & -46.97 & 0.00 & $<0.001$ & $<0.001$ & $<0.001$ \\
\hline Additional labor cost, ${ }^{9} \$$ & 0.00 & -7.25 & -14.50 & -25.38 & 0.00 & $<0.001$ & $<0.001$ & $<0.001$ \\
\hline Additional yardage cost, ${ }^{10} \$$ & 0.00 & 1.55 & -7.75 & -6.20 & 1.49 & $<0.001$ & $<0.001$ & 1.00 \\
\hline Additional feed cost, ${ }^{11} \$$ & 0.00 & 13.36 & -60.25 & -48.56 & 12.0 & $<0.001$ & $<0.001$ & 0.94 \\
\hline Total calf value, ${ }^{12} \$$ & $1,643.80$ & $1,605.93$ & $1,476.91$ & $1,413.35$ & 23.2 & $<0.001$ & $<0.001$ & 0.58 \\
\hline $\begin{array}{l}\text { Total calf value difference from previous } \\
\text { BRDX, \$ }\end{array}$ & 0.00 & -37.87 & -129.02 & -63.57 & 20.9 & 0.002 & 0.006 & 0.02 \\
\hline Total calf value difference from $0 \mathrm{X}, \$$ & 0.00 & -37.87 & -166.89 & -230.46 & 20.9 & $<0.001$ & $<0.001$ & 0.54 \\
\hline
\end{tabular}

${ }^{1}$ Actual prices paid for cattle at the time of slaughter including grid premiums and discounts, and actual costs including antimicrobial costs, yardage costs, and feed costs were used for this economic analysis. The only estimated value was labor cost. The grid base carcass price for all cattle was $\$ 440.64$ per $100 \mathrm{~kg}$ ( $\$ 199.87$ per 100 pounds). The average QG adjustment was $-\$ 4.15$ per $100 \mathrm{~kg}$ ( $\$ \$ 1.88$ per 100 pounds), and the average YG adjustment was $\$ 3.14$ per $100 \mathrm{~kg}$ ( $\$ 1.43$ per 100 pounds).

${ }^{2}$ Number of antimicrobial treatments administered for BRD (BRDX) during the receiving period: never treated for BRD (OX), treated once for BRD (1X), treated twice for BRD (2X), or treated 3 or 4 times for BRD (3/4X).

${ }^{3} P$-values are included for the overall $F$-test and the linear and quadratic contrast for the number of times treated for BRD.

${ }^{4}$ Pen average $Q G$ adjustment based on the premium grid.

${ }^{5}$ Pen average $Y G$ adjustment based on the premium grid.

${ }^{6}$ Pen average actual carcass price based on the premium grid.

${ }^{7}$ Actual carcass price multiplied by HCW.

${ }^{8}$ Actual cost of antimicrobial treatment. The average cost of antimicrobial treatments administered was $\$ 13.73$. For $3 / 4 X$, the antimicrobial cost was averaged for those calves that received 3 or 4 antimicrobials.

${ }^{9} \mathrm{An}$ estimate of $\$ 7.25$ per antimicrobial treatment was assumed to cover the cost of labor.

${ }^{10}$ Actual yardage cost based on pen days on feed relative to $0 \mathrm{X}$. Yardage was $\$ 0.40 /$ steer per $\mathrm{d}$.

${ }^{11}$ Actual feed cost based on pen DMI and days on feed relative to OX. The DM diet cost was $\$ 33.27$ per $100 \mathrm{~kg}$ (\$301.85 per ton).

${ }^{12}$ Total carcass value adjusted for additional costs associated with antimicrobial treatment, labor, yardage, and feed consumption.

slaughter group was included in the model statement for the analysis of carcass quality parameters.

\section{Carcass Value and Economic Analysis}

The average base carcass price on the premium grid used at the slaughter facility was $\$ 440.64$ per $100 \mathrm{~kg}$ (\$199.87 per 100 pounds). This base carcass price was then adjusted for any individual yield and quality premiums or discounts (Table 6) based on the carcass data parameters and then multiplied by the individual HCW for each animal to calculate an individual carcass value for each calf. This carcass value represents the actual price paid for each individual calf at the time of slaughter. After carcass values were calculated for each BRDX group, the actual cost of antimicrobials used in the experiment was subtracted from each respective BRDX group. For 3/4X, the average costs of 3 and 4 antimicrobial treatments was used. Next additional labor and other expenses were accounted for at 
an assumed cost of $\$ 7.25$ per antimicrobial administered. Yardage was then adjusted based on actual DOF for a pen and a yardage cost of $\$ 0.40 /$ steer per d. Finally, feed cost was also adjusted based on actual DMI for a pen and a diet cost of $\$ 33.27$ per $100 \mathrm{~kg}$ ( $\$ 301.85$ per ton) on a DM basis. These adjustments resulted in a total calf value (Table 7). Total calf value was determined as the carcass value adjusted for actual costs resulting from BRD treatment including the purchase price of antimicrobials, increased labor costs associated with treatment and care, adjustments in yardage costs based on variations in DOF, and adjustments in feed costs based on variations in DOF and DMI.

\section{RESULTS AND DISCUSSION}

\section{Experiment Overview and Background Information}

The overall morbidity (66.5\%) and mortality (13.2\%) attributed to BRD for the population of calves used in this experiment fell within the range of expected morbidity and mortality rates for high-risk calves of similar backgrounds at our facility. In other recent experiments conducted at the WSBRC using high-risk, livestock auction-sourced calves purchased during the fall, total morbidity has ranged from 31.4 to $68.0 \%$ (unpublished data). Mortality attributed to clinical BRD in these same experiments ranged from 1.49 to $13.9 \%$. These morbidity and mortality percentages would be supported by surveys and reviews in the literature (Vogel and Parrott, 1994; Edwards, 1996; Smith, 1998; Chirase and Greene, 2001). Bovine respiratory disease is the most common illness in feedlots, affecting $16.2 \%$ of cattle placed on feed (NAHMS, 2013). In addition, it was reported that feedlots in the central region of the United States (Colorado, Kansas, Nebraska, Oklahoma, and Texas) had twice as many cattle affected with BRD than feedlots in the rest of the United States (NAHMS, 2013). It should also be noted that this average includes all cattle received into feedlots, not only high-risk calves as in the case of the current experiment.

An advantage to the increased morbidity and numbers of animals requiring multiple treatments was that it afforded the ability for replication of BRD treatment groups within a finishing experiment. This particular set of calves provided an excellent opportunity to examine our objectives because of the high incidence of naturally occurring BRD within the population. The primary objective of this experiment was to evaluate the effect of BRD incidence during the receiving period on subsequent finishing performance, efficiency, carcass characteristics, and lung scores of feedlot steers.

In our opinion, to accurately determine the effects of BRD incidence, all calves must be allowed to reach their quality and yield potential regardless of the number of BRD treatments received. Obviously, this cannot be accomplished by feeding all calves to equal DOF, so our second objective was to attempt to slaughter each pen of calves at a common compositional endpoint. Our target was to slaughter all pens when calves within that pen reached a 12th-rib fat thickness of $1.27 \mathrm{~cm}$ regardless of DOF. Because of the desired collection of carcass data and lung scores at slaughter combined with the distance to the slaughter facility from WSBRC, logistical concerns compelled us to slaughter calves in as few slaughter groups as possible while maintaining our goal to slaughter all calves at a common compositional endpoint. By using a combination of ultrasound estimates, BW projections, and visual appraisal, we were able to project an ideal individual slaughter date for each pen. After this was accomplished, pens were fairly easily separated into early and late slaughter groups by their individual predicted slaughter dates and all pens were able to be slaughtered in 2 groups (DOF $=166$ or 197). By allowing DOF to fluctuate, all BRDX groups were slaughtered between 1.28 and $1.40 \mathrm{~cm}$ of 12 th-rib fat.

Our final objective aimed to quantify the actual economic losses due to increasing BRDX for a specific group of cattle under recent market conditions. This was accomplished by using the actual carcass prices, grid premiums and discounts, antimicrobial costs, yardage, and feed costs associated with this lot of cattle. Only labor costs were assumed.

After the receiving period, calves remained in their receiving pens for an additional 2 to $3 \mathrm{wk}$ to ensure that all BRD treatments, including up to 4 antimicrobial treatments when necessary, would occur before the finishing period. This approach would also be supported by the literature. Thompson et al. (2006) reported that $87 \%$ of all BRD treatments had occurred within $35 \mathrm{~d}$ of arrival, and Babcock et al. (2009) stated that $74 \%$ of morbidity occurred during the first $42 \mathrm{~d}$ on feed. There was one calf from the $3 / 4 \mathrm{X}$ group that did require BRD treatment after the initiation of the finishing experiment. This calf ultimately died $(\mathrm{DOF}=83)$, and the death was attributed to BRD.

The current experiment was very similar to one conducted by Holland et al. (2010), with the major differences between the experiments being the sex (heifers vs. steers and bulls) and treatment structure of BRDX. Holland et al. (2010) classified BRD treatment groups (BRDX) as never treated for BRD (0X), treated for BRD 1 time (1X), treated for BRD 2 times (2X), treated for BRD 3 times (3X), or chronically ill. In the present experiment, up to 4 antimicrobials were administered, and calves receiving 3 or 4 antimicrobials were combined into a single BRDX group. The majority of calves in the $3 / 4 \mathrm{X}$ group in the present experiment could have been classified as chronically ill according to the classification provided by Holland et al. (2010).

By assembling the BRDX groups the way we did in the present experiment, we were able to provide greater replication of calves experiencing a severe natural BRD challenge and receiving multiple antimicrobial treatments. 
This treatment structure allowed us to have 8 pens per BRDX, even though we had fewer steers in some of the pens receiving multiple BRD treatments. If Holland et al. (2010) had more chronically ill heifers in their experiment and combined them with the $3 \mathrm{X}$ group, the treatment structures would be essentially the same between the 2 experiments.

In the current experiment, calves in the $2 \mathrm{X}$ and $3 / 4 \mathrm{X}$ groups required an additional 17 DOF on average. Holland et al. (2010) also used a similar combination of ultrasound estimates, calf performance, and visual appraisal to target a common compositional endpoint for all heifers. Heifers treated $0 \mathrm{X}, 1 \mathrm{X}$, and $2 \mathrm{X}$ were all slaughtered at the same average DOF, whereas heifers in the $3 \mathrm{X}$ and chronically ill groups were on feed for an average of 19 and 26 more d, respectively (Holland et al., 2010). Waggoner et al. (2007) reported the mean DOF for cattle that were never treated for BRD to be $193 \mathrm{~d}$, for cattle treated 1 time to be 200 $\mathrm{d}$, and for cattle treated 2 or more times to be $212 \mathrm{~d}$. Thomson et al. (2012) reported that calves treated 2 or more times for BRD required an additional 11 DOF. The 11- to 26-d difference in DOF between healthy calves and those treated multiple times for BRD reported by Waggoner et al. (2007), Holland et al. (2010), and Thomson et al. (2012) is consistent with the difference in DOF for the same groups of calves within the present experiment.

\section{Cattle Finishing Performance and Efficiency}

The performance and efficiency data are presented in Table 3. Body weight at arrival (BW taken upon arrival at the WSBRC before the initiation of the receiving experiment) was not different (10-kg difference between $0 \mathrm{X}$ and $3 / 4 \mathrm{X}$ ) for the subpopulation of calves used for the finishing experiment $(P=0.17)$. These results are in agreement with Gardner et al. (1999), Waggoner et al. (2007), Holland et al. (2010), and Thomson et al. (2012), who also noted arrival BW was not different between cattle that were never treated for BRD and cattle that required antimicrobial treatment for clinical signs of BRD. However, the incidence of BRDX during the receiving period did affect calf ADG during this period. As a result, there was a linear decrease $(P<0.001)$ in d-0 BW $(64-\mathrm{kg}$ difference between $0 \mathrm{X}$ and $3 / 4 \mathrm{X}$ ) at the start of the finishing phase. Similarly, Holland et al. (2010) observed a linear decrease in BW as BRDX increased at the start of the finishing phase, resulting from a linear decrease in ADG during the receiving period. This linear decrease in BW during the receiving period associated with increasing BRDX is also supported by data from other experiments (Gardner et al., 1999; Thompson et al., 2006; Schneider et al., 2009; Thomson et al., 2012).

Interval BW obtained on d 45, 91, and 138 all had the same linear decrease $(P<0.001)$ as BRDX increased. During the first $45 \mathrm{~d}$ of the finishing period, there was no difference $(P=0.68)$ in ADG among the BRDX groups. Conversely, from d 46 to 91 and from d 92 to 138 there was a linear increase $(P \leq 0.002)$ in ADG as BRDX increased. This increasing ADG as BRDX increased is evidence of a compensatory gain response as calves previously treated for BRD attempted to compensate for lost performance that occurred during the receiving period. From d 139 to the end of the experiment, this difference in ADG was no longer present $(P=0.40)$. However, when ADG was calculated for the entire finishing period, a linear increase $(P=$ 0.05) in ADG was observed as BRDX increased.

The relative difference in BW among the BRDX groups decreased throughout the finishing period, resulting in a final BW difference of only $16 \mathrm{~kg}$ between $0 \mathrm{X}$ and $3 / 4 \mathrm{X}$ compared with the initial BW difference of $64 \mathrm{~kg}$ between the same 2 BRDX groups. However, there was still a linear decrease $(P=0.01)$ in the final BW taken before slaughter for increasing BRDX. In contrast, Holland et al. (2010) reported no linear differences in the final $\mathrm{BW}$ of heifers for the $0 \mathrm{X}, 1 \mathrm{X}, 2 \mathrm{X}$, and $3 \mathrm{X}$ groups. However, when contrasting $3 \mathrm{X}$ heifers with chronically ill heifers, there was a significant decrease in final BW for chronically ill heifers (Holland et al., 2010). The differing results observed in the final BW of these 2 experiments could simply be the result of how the BRDX groups were structured for those calves receiving 3 or more antimicrobial treatments that suffered from an extreme BRD challenge. Thomson et al. (2012) also reported no differences in final BW even though steers treated 2 or more times for BRD weighed 20 $\mathrm{kg}$ less than untreated steers.

Roeber et al. (2001) and Waggoner et al. (2007) evaluated animals in 2 separate Ranch to Rail programs where animals were also slaughtered on a market-ready basis. Similar to the findings of Holland et al. (2010), final BW was not different among animals administered varying antimicrobial treatments in the 2 Ranch to Rail programs. However, Roeber et al. (2001) and Waggoner et al. (2007) both found a numerical decrease ( 8 and $18 \mathrm{~kg}$, respectively) in final BW for calves requiring 2 or more antimicrobial treatments. In a review of individual carcass characteristics of 33,073 steers fed in commercial pens linked to previous BRD treatments, Erickson et al. (2011) reported a significant linear decrease in final BW among steers as BRDX increased.

Much of the data investigating the effects of BRD on feedlot cattle performance and carcass characteristics results from correlating individual cattle performance to treatment records on a retrospective basis (Roeber et al., 2001; Waggoner et al., 2007; Garcia et al., 2010). This retrospective approach has also been conducted using the presence of lung lesions or lung scores at slaughter (Gardner et al., 1999; Thompson et al., 2006; Schneider et al., 2009). Finally, other experiments have simply evaluated the performance of a single pen or lot of cattle with high incidence of BRD (Thomson et al., 2012). These experiments can provide good evidence of performance of treated cattle on a large commercial scale. However, none of these methods are ideal, because they either cannot 
account for DMI and efficiency measures, or they simply lump nontreated and cattle receiving differing numbers of BRD treatments within a pen or lot together to determine intake and efficiency of the pen or lot.

The treatment structure of the present experiment allowed for the measurement of DMI of feedlot cattle that had required different numbers of antimicrobial treatments for BRD during the receiving period. Obviously, without knowing which calves would eventually require treatment, we were not able to measure intake during the receiving period, but previous data would suggest that the morbid calves in our experiment were likely consuming less feed than healthy animals during this time. It is likely that much of the decrease in prefinishing ADG observed in the current experiment by calves that required antimicrobial treatment for BRD could be the result of altered feeding behavior and decreased DMI by these calves. Because all calves in the present experiment received the same diets during both the receiving and finishing phases, differences in performance resulting from nutrition would primarily be related to differences in DMI by morbid animals.

High-risk calves have been shown to have altered eating patterns when compared with unstressed cohorts (Galyean et al., 1999). In addition, the DMI of high-risk calves is extremely variable, and many calves do not achieve adequate DMI for the first couple of weeks on feed. Hutcheson and Cole (1986) stated that DMI for newly received calves ranged from 0.5 to $1.5 \%$ of $\mathrm{BW}$ and that the majority of morbid calves do not consume any feed for the first $2 \mathrm{~d}$ in the feedlot. It was also reported that only $83.4 \%$ of morbid calves were consuming feed by the end of the first week in the feedlot (Hutcheson and Cole, 1986). These results cause sick calves to have only 58,68 , and $88 \%$ of the DMI compared with healthy animals during the first, fourth, and eighth weeks after arrival in the feedlot (Hutcheson and Cole, 1986).

There was a linear decrease $(P=0.004)$ in DMI observed from the start of the finishing period until d 45 as BRDX increased. This DMI depression during the first interval of the finishing period for calves that required antimicrobial treatment for BRD is likely a carryover effect from the receiving period. These results would be similar to those reported by Holland et al. (2010), who noted a linear decrease in DMI during the first 65 DOF. There was a tendency $(P=0.07)$ for DMI to be different from $\mathrm{d}$ 92 through 138; however, there was no linear or quadratic trend $(P \geq 0.12)$. No other differences in DMI $(P \geq 0.49)$ were detected among the BRDX groups. When DMI was evaluated as a percentage of average $\mathrm{BW}$ for the feeding period, a BRDX $\times$ ANC interaction $(P \leq 0.03)$ was observed for d 92 through 138 and d 139 to final. A significant linear increase $(P \leq 0.001)$ was observed for all other intervals as well for the entire finishing period for DMI as a percentage of average BW. This increase in DMI as a percentage of BW would serve as additional evidence of the attempted compensation for reduced performance that occurred during the receiving period among antimicrobial treated calves. Holland et al. (2010) reported a linear increase or a tendency for linear increase in DMI as a percentage of BW over 2 intervals but no difference in DMI as a percentage of BW over the length of the experiment.

Gain:feed was not different $(P=0.20)$ among BRDX during the first $45 \mathrm{~d}$ of the finishing period. However, the increase in ADG with increasing BRDX from d 46 to 91 and from d 92 to 138 combined with similar DMI among BRDX groups during these same intervals resulted in linear increases $(P \leq 0.01)$ in $\mathrm{G}: \mathrm{F}$ over the subsequent 2 intervals. From d 139 to the end of the experiment, this difference in $\mathrm{G}: \mathrm{F}$ was no longer present $(P=0.26)$; calves in the $2 \mathrm{X}$ and $3 / 4 \mathrm{X}$ groups became numerically less efficient, resulting in overall G:F not being significantly different $(P=0.22)$ among the BRDX groups. This result was in contrast to the efficiency data reported by Holland et al. (2010), who noted a linear increase in overall G:F with increasing BRDX.

\section{Common Compositional Endpoint Projections and DOF}

On d 91, ultrasound estimates (Table 4) indicated that there was a tendency for a BRDX $\times$ ANC interaction $(P$ $=0.08)$ for REA, whereas intramuscular fat tended $(P=$ $0.10)$ to decrease linearly (linear, $P=0.06$ ) as the number of BRD treatments increased. By d 138, there was still a linear decrease $(P=0.01)$ in ultrasound REA as BRDX increased, but there was no longer a difference $(P=0.32)$ in intramuscular fat according to ultrasound. The 12th-rib fat thickness of calves was not different $(P \geq 0.21)$ among BRDX groups at d 91 or 138 according to ultrasound estimates.

Days on feed (Table 3$)$ did increase linearly $(P=0.002)$ as BRDX increased. At slaughter, there were no differences $(P=0.83)$ in compositional maturity based on 12thrib fat thickness among any of the BRDX groups. There was a numerical increase in 12th-rib fat thickness for $2 \mathrm{X}$ and $3 / 4 \mathrm{X}$ calves compared with $0 \mathrm{X}$. Based on the measure of 12th-rib fat thickness as well as overall carcass fat evidenced through KPH percentage and USDA YG, we were successful at slaughtering all steers at the same compositional endpoint. Only a 0.12 -cm difference in the average 12th-rib fat thickness was observed between steers across BRDX treatment groups. Cattle in the $3 / 4 \mathrm{X}$ group were finished to the greatest numerical fat thickness, and there was a numerical increase in 12th-rib fat thickness observed for both $2 \mathrm{X}$ and $3 / 4 \mathrm{X}$ calves compared with $0 \mathrm{X}$. We wanted to ensure that $2 \mathrm{X}$ and $3 / 4 \mathrm{X}$ calves had every opportunity to reach the same quality and yield grades as the OX calves. By ensuring that calves treated multiple times for BRD had slightly greater fat thickness, we were confident that these calves were given ample time to reach their quality and yield potential. These results were similar to those described by Holland et al. (2010), who also reported no differences in 12th-rib fat and overall carcass fatness, except for in the chronically ill heifers. 


\section{Carcass Characteristics and Lung Consolidation and Adhesion Scores}

Hot carcass weight followed the same pattern as final BW, with increasing BRDX resulting in a linear decrease $(P<0.001)$ in HCW. There was also a linear decrease $(P<0.001)$ in DP that further affected HCW. This was in contrast to the data reported by Holland et al. (2010), who noted no linear differences in $\mathrm{HCW}$ or DP with increasing BRDX. Similarly, Thomson et al. (2012) reported no difference in HCW among BRD treatment groups. The results reported by Roeber et al. (2001) support the findings of the present experiment. Roeber et al. (2001) reported that there was a significant decrease in both $\mathrm{HCW}$ and DP for calves receiving 2 or more antimicrobial treatments compared with calves not treated. In a review of large-pen data from commercial feedlots by Erickson et al. (2011), a significant linear decrease in HCW was observed among steers as BRDX increased.

Rib eye area also decreased in a linear fashion $(P=$ 0.03 ) when BRDX increased. However, when REA was evaluated as a percentage of $\mathrm{HCW}$, no differences were observed among the BRDX groups $(P=0.52)$. This would suggest the reduction in REA observed in the present experiment is primarily the result of decreased HCW as BRDX increases. The decrease in REA was in contrast to the results of Holland et al. (2010) and Thomson et al. (2012), who reported no differences in the REA of calves with increasing BRDX. Roeber et al. (2001) and Waggoner et al. (2007) also reported no significant decrease in REA with increasing BRD treatments; however, both did find a numerical decrease in the REA of calves requiring 2 or more antimicrobial treatments. Erickson et al. (2011) reported a significant linear decrease in the REA of steers in commercial feedlots as BRDX increased.

There was a linear decrease $(P=0.03)$ in the percentage of USDA Prime and Choice carcasses as BRDX increased. These findings were different than those of Holland et al. (2010), who reported no difference in the percentages USDA Choice or Select carcasses among the BRD treatment groups. Thomson et al. (2102) also reported no difference in the percentage of QG among untreated calves and calves treated for BRD. There was a BRDX $\times$ ANC interaction $(P=0.03)$ for marbling score. No differences $(P \geq 0.26)$ for 12 th-rib fat thickness, KPH, marbling score, USDA YG, or liver score were observed among the BRDX groups. These results are similar to those described by Holland et al. (2010), who reported a tendency for a linear decrease in marbling score as BRDX increased. In the present experiment there was a numerical decrease in marbling score as BRDX increased, but this difference of 45 units from Small ${ }^{16}$ to Small ${ }^{51}$ was not statistically significant. Thomson et al. (2012) reported no difference in marbling score or USDA YG but did report a linear decrease in 12th-rib fat thickness as BRDX increased. In the current experiment and the experiment conducted by Holland et al. (2010), 12th-rib fat thickness was a major criterion for projecting target slaughter dates and evaluating compositional endpoints. Based on the difference in fat thickness in the experiment by Thomson et al. (2012), it could be argued that calves were not fed to the same common compositional endpoint in that experiment.

The decrease in QG and numerical decrease in marbling score with increased morbidity in the present experiment are similar to those reported elsewhere in the literature. Schneider et al. (2009) reported that 16\% fewer calves that were treated for BRD graded USDA Choice than nontreated calves. Roeber et al. (2001) reported that there was a significant decrease in marbling score for calves receiving 2 or more antimicrobial treatments. In the review of large-pen data from commercial feedlots, Erickson et al. (2011) reported significant linear decreases in both marbling score and the percentage of USDA Choice carcasses of steers as antimicrobial treatments for BRD increased. However, the effects of BRD treatment on QG and marbling score have been inconsistent. Waggoner et al. (2007) and Garcia et al. (2010) reported no decrease in marbling score for cattle requiring BRD treatment. However, Garcia et al. (2010) did observe a tendency for cattle treated for BRD that were derived from sires of 7 Bos taurus breeds to have a decreased percentage of USDA Choice carcasses.

The percentage of calves with lung consolidation scores of 0 decreased linearly $(P<0.01)$ as BRDX increased. In addition, the percentage of calves with lung consolidation scores of 2 increased linearly $(P=0.04)$ as BRDX increased. There was also a numerical $(P=0.45)$ increase in the percentage of calves with lung consolidation scores of 3 observed for $2 \mathrm{X}$ and $3 / 4 \mathrm{X}$ calves compared with $\mathrm{OX}$ and $1 \mathrm{X}$. This is in contrast to the results from Holland et al. (2010), where no significant differences were reported for any of the lung score data. Conversely, there were no differences $(P=0.33)$ in lung adhesion among BRDX groups in the present experiment.

In theory, the majority of cattle that suffered from BRD would have lung lesions present at slaughter. Wittum et al. (1996) and Bryant et al. (1999) reported that the presence of pulmonary lesions was a better predictor than antibiotic treatment records for losses in ADG resulting from BRD. One reason for this finding is that cattle that were never treated for clinical signs of BRD frequently had evidence of lung damage at slaughter. However, using the presence of lung lesions at slaughter as a predictor of previous BRD incidence is not without fault, becuase it has also been reported that cattle that have be treated for clinical signs of BRD have lacked the presence of any detectable pulmonary lesions at slaughter (Wittum et al., 1996; Gardner et al., 1999; Thompson et al., 2006; Schneider et al., 2009).

Holland et al. (2010) argued that even though the lung lesion data were not different between the BRD treatment groups in their experiment, the differences in preconditioning phase performance, combined with increased haptoglobin concentrations and rectal temperatures in treated heifers, indicated that the BRD treatments administered 
were related to an active infection. Currently, there is no perfect diagnostic tool to determine the incidence of BRD in feedlot cattle, and thus, determining the true production and economic losses due to BRD is extremely difficult. However, we would agree with the assessment of Holland et al. (2010) that measuring finishing performance, carcass characteristics, and ultimately economic losses due to BRD based on antimicrobial treatment for the clinical signs of BRD is appropriate and accurate.

\section{Carcass Value and Economic Analysis}

It has been well documented that as BRD treatments increase, carcass values and overall net return per animal can exponentially decrease. Waggoner et al. (2007) reported the mean loss in total value for cattle that were treated one time to be $\$ 28.52 /$ head and the mean loss in total value for cattle treated 2 or more times to be $\$ 172.67 /$ head. Schneider et al. (2009) reviewed the records from 5,976 animals fed in midwestern feedlots and reported similar results for the economic impact of one BRD treatment (\$23.23); however, the economic loss resulting from multiple antimicrobial treatments was not as severe ( $\$ 30.15$ and $\$ 54.01$ for 2 and 3 BRD treatments, respectively). The authors observed that decreases in animal performance and carcass merit were associated with a decrease of $\$ 23.23, \$ 30.15$, and $\$ 54.01$ in carcass value for cattle treated for BRD 1, 2, or 3 or more times, respectively, when compared with cattle never treated for BRD (Schneider et al., 2009).

As with any economic analyses, the economic values presented for this experiment are specific to the population of cattle in the current experiment and the prices and market conditions at the time the cattle were marketed. These values are dependent on the price of cattle at the time of slaughter, the choice select spread, and individual grid premiums and discounts. In addition, the cost of inputs greatly affects the total value of cattle at slaughter. As an example, the average cost per antimicrobial treatment administered in this experiment was $\$ 13.73$. However, NAHMS (2013) reported that the average cost of antimicrobial treatment for BRD in all feedlots was $\$ 23.60$.

The economic data for the current experiment are presented in such a way that readers are able to use current market values specific to their production setting or region to critically evaluate the economics of BRDX. By presenting the data this way, any carcass price, grid premium or discount, antimicrobial cost, labor cost, yardage, and feed cost can be used to estimate the economic impact of BRDX under any simulated or real market conditions. Regardless of how the economic data presented are viewed, to accurately estimate the total economic losses resulting from BRD, we recommend that calves treated for BRD be allowed additional DOF to reach similar compositional endpoints compared with untreated cohorts and that all costs associated with BRD treatment and the additional DOF be considered.
The average carcass price per $100 \mathrm{~kg}$ was not different $(P=0.25)$ among BRDX groups and ranged from $\$ 436.48$ to $\$ 443.16$ ( $\$ 197.99$ to $\$ 200.41$ per 100 pounds). However, decreases in BW and DP as BRDX increased resulted in larger differences in total carcass value as BRDX increased. Calves never treated for BRD had an average carcass value of $\$ 1,643.80$, whereas $1 \mathrm{X}, 2 \mathrm{X}$, and $3 / 4 \mathrm{X}$ groups returned $\$ 1,612.67, \$ 1,589.01$, and $\$ 1,540.46$, respectively, resulting in a linear decrease $(P=0.001)$ in total carcass value. When total calf value was calculated by adjusting for the cost of antimicrobials, increased labor, and variation in yardage and feed consumption due to differences in DOF, the differences in value among BRDX groups became more magnified. The total calf value for $0 \mathrm{X}$ remained the same, whereas $1 \mathrm{X}, 2 \mathrm{X}$, and $3 / 4 \mathrm{X}$ groups had total calf values of $\$ 1,605.93, \$ 1,476.91$, and $\$ 1,413.35$, respectively (linear $P<0.0001$ ). These differences in total calf value resulted in a reduction of $\$ 37.87, \$ 166.89$, and $\$ 230.46$ for $1 \mathrm{X}, 2 \mathrm{X}$, and $3 / 4 \mathrm{X}$, respectively, when compared with 0X. Brooks et al. (2011) examined the economic impact of BRD treatments for the heifers in the experiment conducted by Holland et al. (2010). Interestingly, heifers treated once for BRD returned $\$ 10.12$ per head more than those heifers never treated (Brooks et al., 2011). However, heifers treated 2 times, 3 times, or deemed chronically ill returned $\$ 11.08, \$ 72.01$, and $\$ 143.28$ less per head than those heifers never treated (Brooks et al., 2011).

In the current experiment, the greatest single economic loss experienced by all calves that were treated for BRD was a loss of carcass value at the time of slaughter. The second greatest economic loss for $1 \mathrm{X}$ calves was due to antimicrobial cost. The second greatest economic loss for $2 \mathrm{X}$ and $3 / 4 \mathrm{X}$ calves was due to increased feed cost resulting from increased DOF. Calves in the $1 \mathrm{X}$ group received a positive adjustment for yardage and feed cost due to a numerical decrease in DOF resulting from a numerical increase in performance compared with calves in the $0 \mathrm{X}$ group.

\section{IMPLICATIONS}

With additional DOF, calves treated multiple times for BRD can reach the same compositional endpoint as untreated cohorts. The additional DOF results in increased costs but also allows for compensation of lost performance and recovery of economic losses incurred early in the feeding period. Consequently, the railing or realizing of calves treated multiple times for BRD would not be recommended because losses can be minimized if these calves are allowed additional DOF and marketed as finished cattle. However, these calves will likely never achieve equivalent carcass yields, USDA QG, and, consequently, carcass value as calves never treated for BRD. Therefore, the economic losses of calves requiring multiple BRD treatments can be ameliorated with additional DOF, but not eliminated. In this experiment, the incidence of clinical BRD resulted in 
a $2.3,10.2$, and $14.0 \%$ decrease in total value for calves treated once, twice, and 3 or 4 times, respectively.

\section{ACKNOWLEDGMENTS}

The authors wish to thank the employees of the Willard Sparks Beef Research Center for assisting with this experiment. This project was funded by the Oklahoma Agricultural Experiment Station.

\section{LITERATURE CITED}

Babcock, A. H., B. J. White, S. S. Dritz, D. U. Thomson, and D. G. Renter. 2009. Feedlot health and performance effects associated with the timing of respiratory disease treatment. J. Anim. Sci. 87:314-327.

Brooks, K. R., K. C. Raper, C. E. Ward, B. P. Holland, C. R. Krehbiel, and D. L. Step. 2011. Economic effects of bovine respiratory disease on feedlot cattle during backgrounding and finishing phases. Prof. Anim. Sci. 27:195-203.

Bryant, L. K., L. J. Perino, D. Griffin, A. R. Doster, and T. E. Wittum. 1999. A method of recording pulmonary lesions of beef calves at slaughter, and the association of lesions with average daily gain. Bov. Pract. 33:163-173.

Chirase, N. K., and L. W. Greene. 2001. Dietary zinc and manganese sources administered from the fetal stage onwards affect immune response of transit stressed and virus infected offspring steer calves. Anim. Feed Sci. Technol. 93:217-228.

Duff, G. C., and M. L. Galyean. 2007. Board-Invited Review: Recent advances in management of highly stressed, newly received feedlot cattle. J. Anim. Sci. 85:823-840.

Edwards, A. 1996. Respiratory disease of feedlot cattle in central U.S.A. Bov. Pract. 30:5-7.

Erickson, G. E., V. R. Bremer, T. J. Klopfenstein, D. R. Smith, K. J. Hanford, R. E. Peterson, L. O. Burciaga-Robles, D. B. Faulkner, and C. R. Krehbiel. 2011. Relationship between morbidity and performance in feedlot cattle. Nebraska Beef Cattle Report. Univ. Nebraska, Lincoln. Accessed Mar. 19, 2014. http://digitalcommons. unl.edu/animalscinbcr/608.

Galyean, M. L., L. J. Perino, and G. C. Duff. 1999. Interaction of cattle health/immunity and nutrition. J. Anim. Sci. 77:1120-1134.

Garcia, M. D., R. M. Thallman, T. L. Wheeler, S. D. Shackelford, and E. Casas. 2010. Effect of bovine respiratory disease and overall pathogenic disease incidence on carcass traits. J. Anim. Sci. 88:491-496.

Gardner, B. A., H. G. Dolezal, L. K. Bryant, F. N. Owens, and R. A. Smith. 1999. Health of finishing steers: Effects on performance, carcass traits, and meat tenderness. J. Anim. Sci. 77:3168-3175.

Hodgins, D. C., J. A. Conlon, and P. E. Shewen. 2002. Respiratory viruses and bacteria in cattle. In Polymicrobial Diseases. K. A. Brogden and J. M. Guthmiller, ed. ASM Press, Washington, DC. Accessed Mar. 19, 2014. http://www.ncbi.nlm.nih.gov/books/NBK2480/.

Holland, B. P., L. O. Burciaga-Robles, D. L. VanOverbeke, J. N. Shook, D. L. Step, C. J. Richards, and C. R. Krehbiel. 2010. Effect of bovine respiratory disease during preconditioning on subsequent feedlot performance, carcass characteristics, and beef attributes. J. Anim. Sci. 88:2486-2499.

Hutcheson, D. P., and N. A. Cole. 1986. Management of transit stress syndrome in cattle nutritional and environmental effects. J. Anim. Sci. 62:555-560.
NAHMS (National Animal Health Monitoring System). 2013. Feedlot 2011. Part IV: Health and Health Management on U.S. Feedlots with a Capacity of 1,000 or More Head. USDA-Anim. Plant Health Inspect. Serv.-Vet. Serv.-Natl. Anim. Health Monit. Syst., Ft. Collins, CO.

NCBA. 2001. Beef Quality Assurance National Guidelines. Natl. Cattlemen's Beef Assoc., Washington, DC. Accessed Nov. 27, 2011. http://www.bqa.org/Media/BQA/Docs/nationalmanual.pdf.

NRC. 2000. Nutrient Requirements of Beef Cattle: Update 2000. 7th ed. Natl. Acad. Press, Washington, DC.

Powell, J. 2013. Livestock health series: Bovine respiratory disease. Div. Agric. Fact Sheet FSA3082. Univ. Arkansas, Fayetteville, AR. Accessed Jul. 9, 2014. http://www.uaex.edu/publications/pdf/FSA3082.pdf.

Roeber, D. L., N. C. Speer, J. G. Gentry, J. D. Tatum, C. D. Smith, J. C. Whittier, G. F. Jones, K. E. Belk, and G. C. Smith. 2001. Feeder cattle health management: Effects on morbidity rates, feedlot performance, carcass characteristics, and beef palatability. Prof. Anim. Sci. $17: 39-44$

Schneider, M. J., R. G. Tait Jr., W. D. Busby, and J. M. Reecy. 2009. An evaluation of bovine respiratory disease complex in feedlot cattle: Impact on performance and carcass traits using treatment records and lung scores. J. Anim. Sci. 87:1821-1827.

Smith, R. A. 1998. Impact of disease on feedlot performance: A review. J. Anim. Sci. 76:272-274.

Step, D. L., C. R. Krehbiel, H. A. Depra, J. J. Cranston, R. W. Fulton, J. G. Kirkpatrick, D. R. Gill, M. E. Payton, M. A. Montelongo, and A. W. Confer. 2008. Effects of commingling beef calves from different sources and weaning protocols during a forty-two-day receiving period on performance and bovine respiratory disease. J. Anim. Sci. 86:3146-3158.

Thompson, P. N., A. Stone, and W. A. Schultheiss. 2006. Use of treatment records and lung lesion scoring to estimate the effect of respiratory disease on growth during early and late finishing periods in South African feedlot cattle. J. Anim. Sci. 84:488-498.

Thomson, D. U., E. S. Moore, B. J. White, and C. D. Reinhardt. 2012. Case study: Effects of undifferentiated bovine respiratory disease on performance and marbling deposition in feedlot steers fed to a common yield grade endpoint. Bov. Pract. 46:52-58.

Vogel, G. L., and J. C. Parrott. 1994. Mortality survey in feedyards: The incidence of death from digestive, respiratory and other causes in feedyards of the Great Plains. Compend. Contin. Educ. Pract. Vet. $16: 227-234$.

Waggoner, J. W., C. P. Mathis, C. A. Loest, J. E. Sawyer, F. T. McCollum, and J. P. Banta. 2007. Case Study: Impact of morbidity in finishing beef steers on feedlot average daily gain, carcass characteristics, and carcass value. Prof. Anim. Sci. 23:174-178.

Wilson, B. K., D. L. Step, C. L. Maxwell, J. J. Wagner, C. J. Richards, and C. R. Krehbiel. 2015. Evaluation of multiple ancillary therapies used in combination with an antimicrobial in newly received high-risk calves treated for bovine respiratory disease. J. Anim. Sci. 93:3661-3674.

Wittum, T. E., N. E. Woollen, L. J. Perino, and E. T. Littledike. 1996. Relationships among treatment for respiratory tract disease, pulmonary lesions evident at slaughter, and rate of weight gain in feedlot cattle. J. Am. Vet. Med. Assoc. 209:814-818.

Woolums, A. R., G. H. Loneragan, L. L. Hawkins, and S. M. Williams. 2005. Baseline management practices and animal health data reported by US feedlots responding to a survey regarding acute interstitial pneumonia. Bov. Pract. 39:116-124. 